\title{
التنقيب في عملية تحويل جماعة إلى أقلية
}

\begin{abstract}
Les coptes d'Egypte: Violences communautaires et transformations politiques : : الكتاب

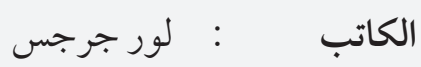

مكان النشر باريس

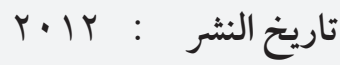

Karthala et IISMM : :

عدد الصفحات: ع بر ب
\end{abstract}

السياسي"(1) ، و أبحاث عن الكنيسة القبطية(r)

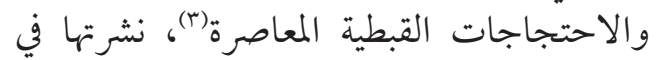

$$
\text { كتب مشتر كة. }
$$

لا شك أنه صدر بشأن أقباط مصر في العقود الثلاثة

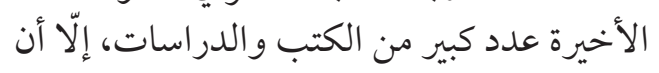
اختيار كتاب لور جر جس للمراجعة كان كان لسبيبن:

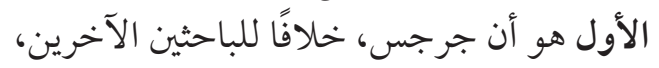

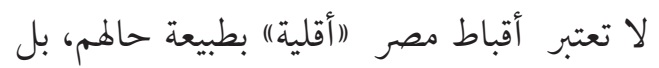

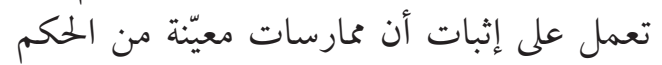

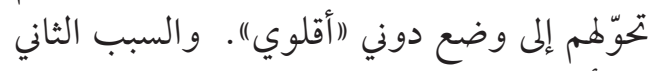
هو أنها اعتمدت منهجية جديدة (غير مسبوقة في
المؤلفة لور جرجس باحثة مصرية في العلوم السياسية والفلسفة السياسية. عملت سنوات عدة لإنجاز هذه الأطروحة

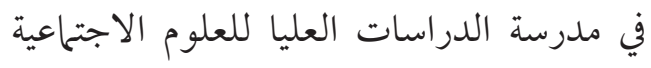
(EHESS)

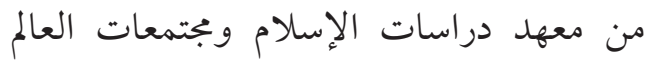
الإسلامي (IISMM). تو اصل المؤلفة حاليًا أبحاثها في جامعة مونتريال-

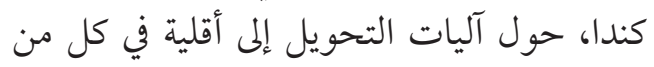

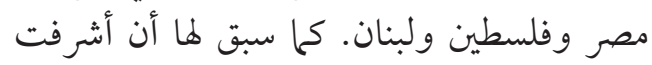
على إصدار كتاب حول اعتناق دين آخر و التحول 
سجالات المجلس النيابي، وفي سرديات حزب الوسبات

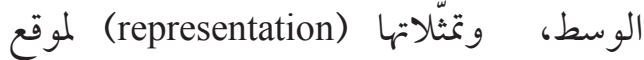
الأقباط داخل الوطني وعلى مستوى الأمة.

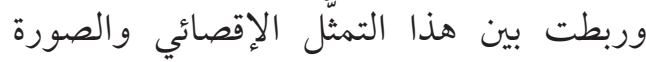
النمطية المتخيَّلة لـ (الفتيات القبطيات المخططوفات المئي والمزوَّجات قسرًا من شبان مسلمين، إنكارًا

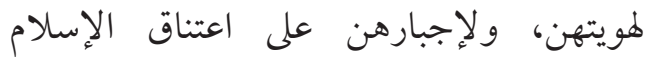

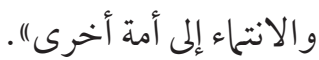

وتقابل هذه (الهويات المرغوب فيها) لفتيات الأقلية بـ (الهويات الممنوعة) عن شبان المنان الأكثرية

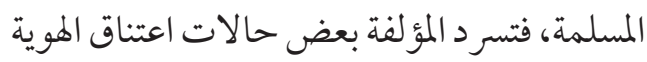

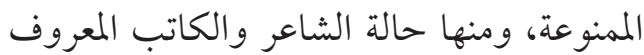

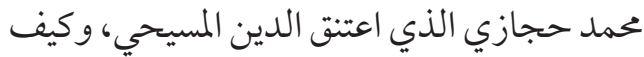

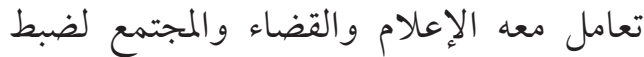
هذه الحالة من الارتداد عن الإسلام واعتناق دين آخر. وترسم المؤلفة بشكل دقيق الرادئ الرموز

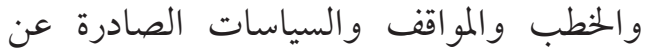
الحكم والسلطة والقوى الاجتماعية والمؤسسات

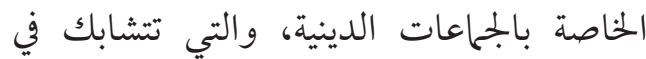
الحالات المدروسة لتؤدي إلى إنتاج الحالة الأقلية وإعادة إنتاجها.

تتنقل جرجس في الجزء الثاني إلى مستوى

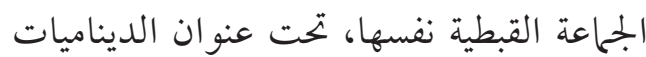

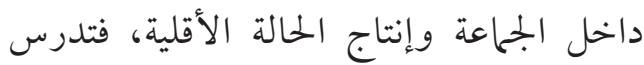

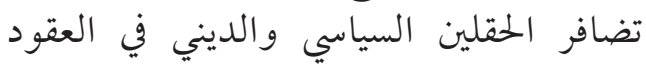
الأربعة الأخيرة في إحداث تحوّلات حاسمة الكين

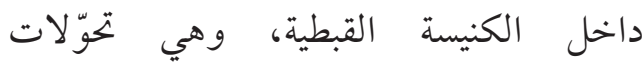

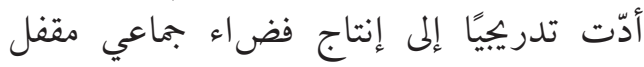

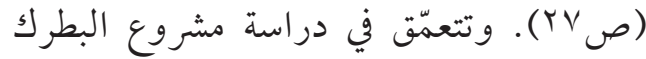

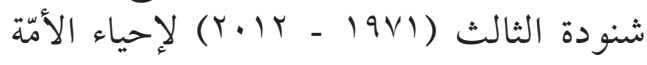

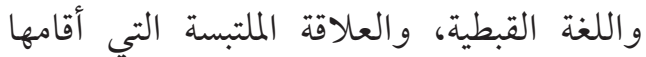
بين الكنيسة ونظام حسني مبارك. كما تتوقف

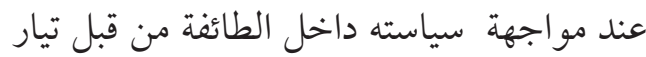
(العلمانيين)، وأخيرًا الصراع حول خلافته، فتبينين
الأبحاث العربية) لدراسة موضوع الأقليات، تصلح لدراسة أوضاع نختلف الجماعات المميّزة

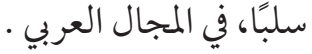

وبالتالي، فإن الجديد والمفيد في دراستها هو كشفها آليات التحويل إلى أقلية، واستتناجها ألمانيات أن تغيير

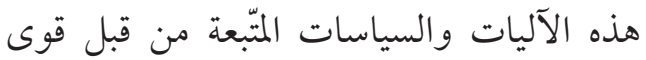

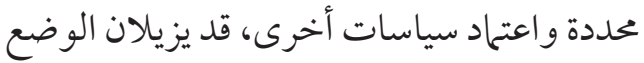

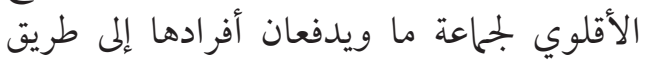
الانتحاء المتساوي في المو اطنة.

وقد استفادت المؤلفة من المنهجية التاريخية التنقيبية (Archeologique) التي بناها وطبّقها العالم الفرنسي ميشيل فوكو في أبحاثه بشأن النانيا

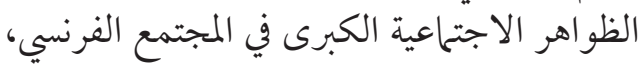

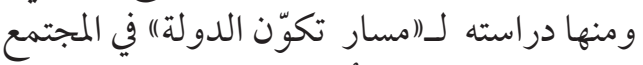

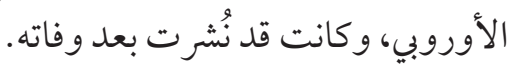

الموضوع ركزت المؤلفة على الفترة الأخيرة من عهد مبارك

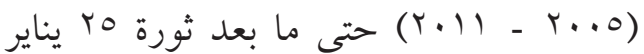

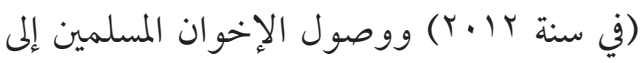

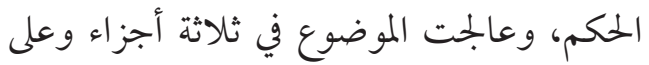

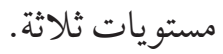

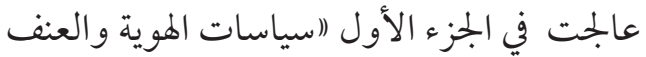

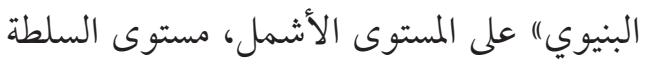

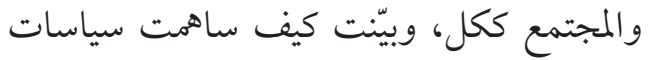
الحكو مات المتتالية في إنتاج الفتنة الطائفية وأشكال

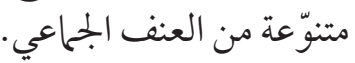

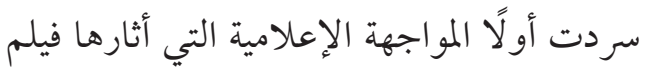

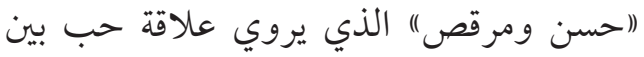

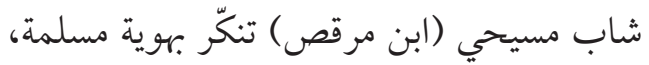

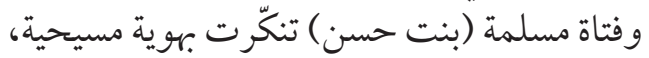
والعلاقة بين عائلتيها على خلفية الحرب النيات الأهلية

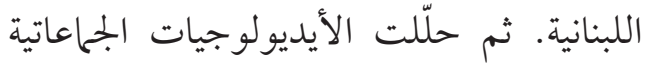
(communautaristes) 
وهي تتّسم (عشية الثورة) بالانحدار أكثر فأكثر

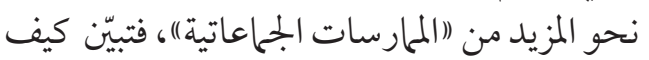

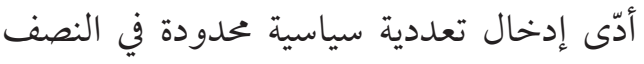
الأخير من عهد مبارك، إلى المزيد من السلوك

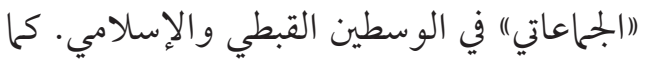

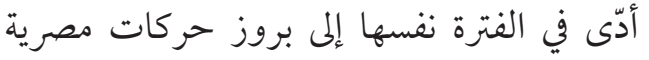

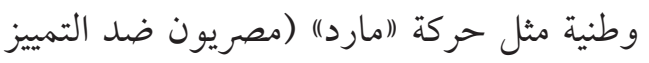
الديني) التي قاومت شتى أنواع التمييز الديني.

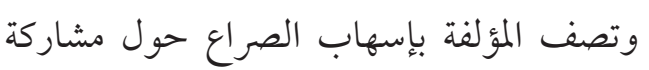
الأقباط في الانتخابات النيابية، ورفضهم التصني التمثيل النسبي المناطقي، وسلوك قوى الإستانيات الإنام السياسي

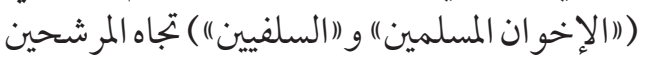
الأقباط، في نظام التحالفات، وإعادة إنتاج النظام

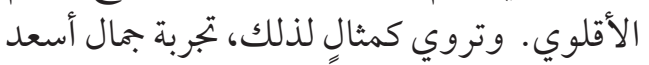

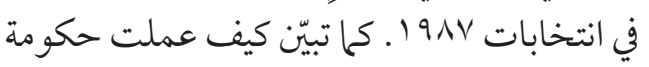

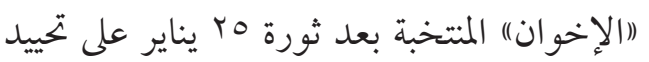

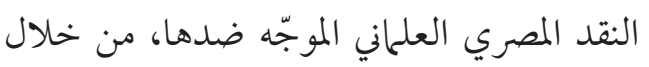

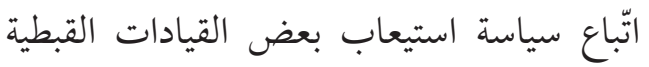
واستبعاد البعض الآخر.

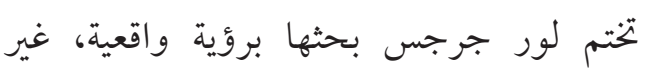

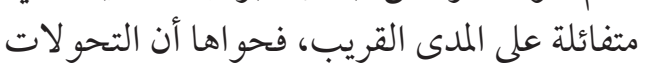

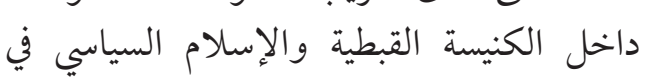

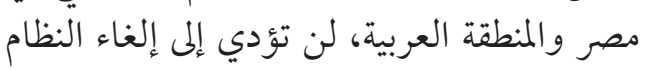
الجحاعاتي المبني على مبدأي الهيمنة والإقصاء.

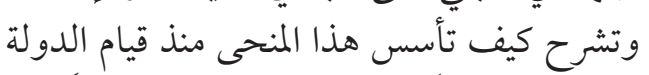

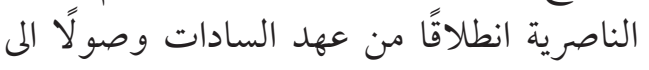

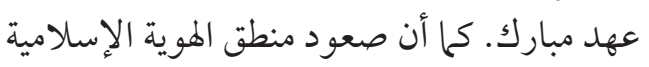
في صيغتها الحديثة، أدّى إلى تغيّر طرق التئ التمييز تجاه

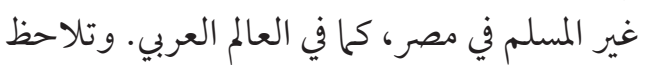

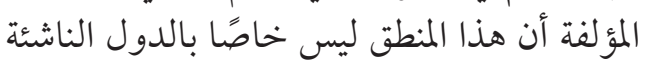

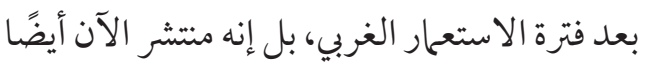

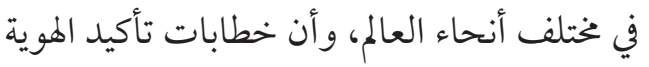

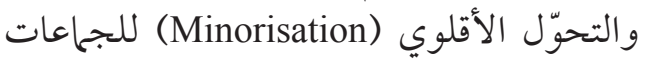
الأقل عددًا والأضعف موقعًا، تعمل داخل معظم
كيف تعمّق مسار التحوّل إلى أقلية على الرغم من مدمار

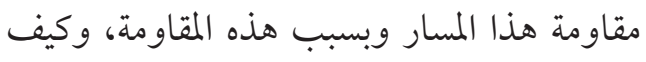
تكوّن تدرييًا الوضع الأهلي وبني على المستويين المؤسسي و الرمزي.

لتمثيل هذا التحوّل، تسرد المؤلفة واقعة وفاء

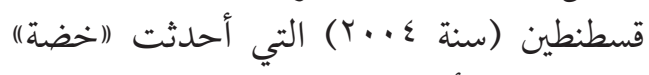

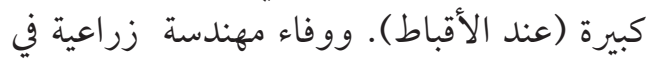

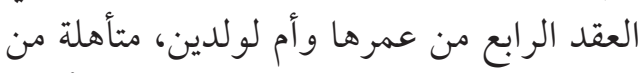
كاهن قبطي يعاني مرض السكري الذي الذي أقعده

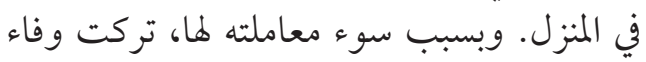

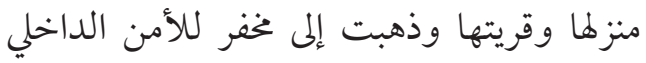

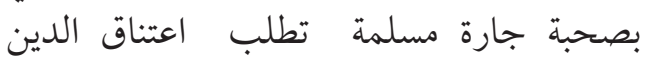

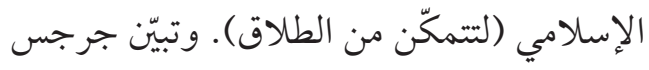

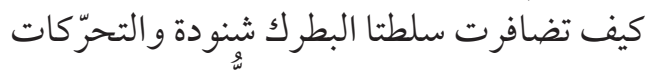

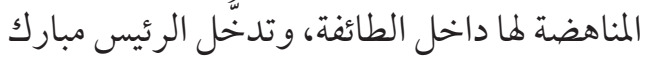
والقضاء، لإجبار وفاء على العودة إلى الكنيسة المئية والتراجع عن طلبها. كما تُظهِر المؤلفة بصورة لافتة كيف ولّمبته السلطة الكنسية نقيضها بسبب هيمنتها المتصاعدة

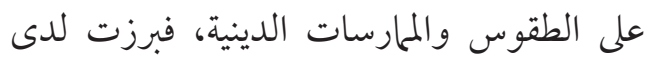

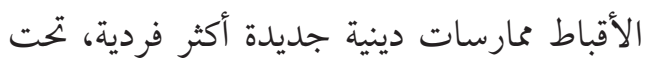

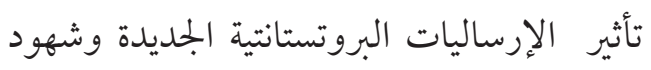

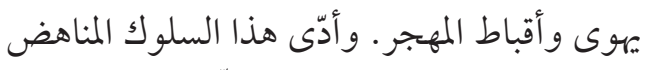

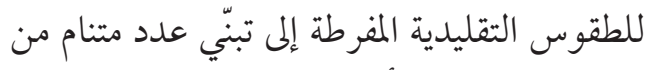

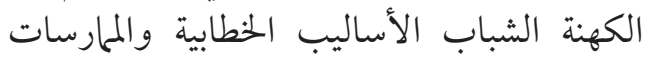

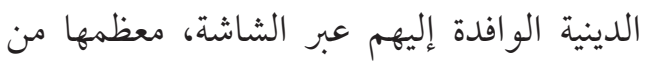

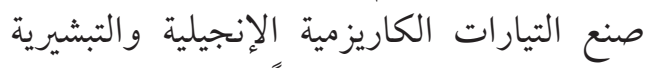

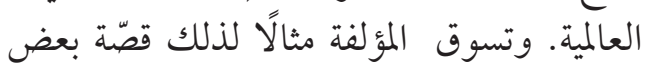

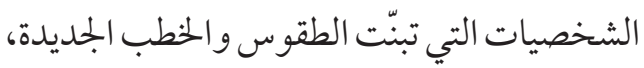
مثل أبونا سمعان، راعي الأقباط العاملين في مزبلة المطبلة المقطّم، ومكاري يونان وزكريا بطرس.

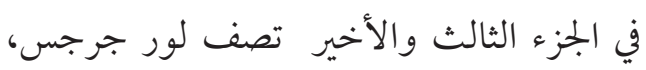

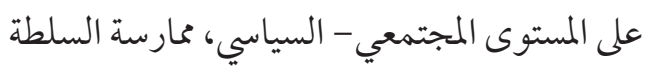

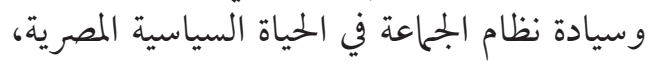


المواطنين وفي بجالات الحياة العامة كافة. ربيا يبرز الجديد في بحث جرجس إذا ما قورن

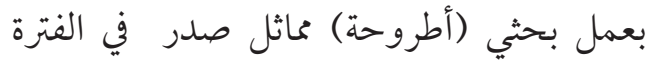
عينها للباحثة مي مجيب مسعد، عنو اله الهي الأقباط

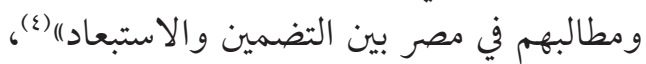
فيظهر الاختلاف بين البحثين في فرضيتها الرئيسة

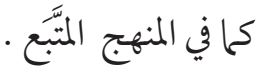

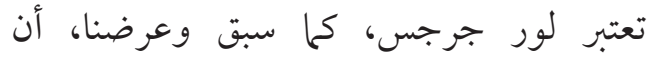
سياسات السلطة الحاكمة وسلوكيات الجماعات

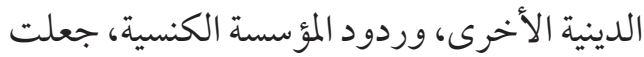

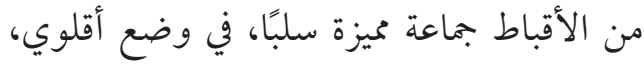

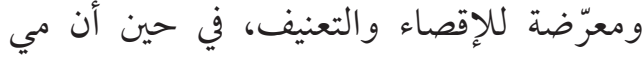
جبيب عالجت الحالة القبطية من زاويتين: سياسات (الاستبعاد) (أو العزل) التي تجعلهم قلّة علئة عدديّة كميزة سلبًا، وعكسها، سياسات (التضمين) التئي التئي

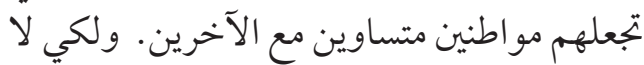

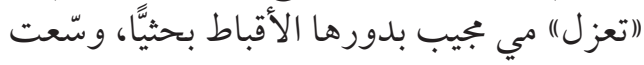

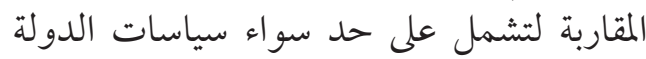

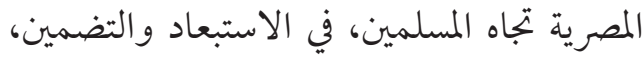

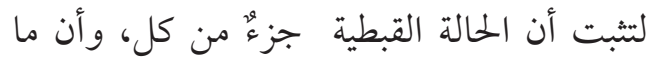
يختلف في سياسات الدولة إزاء الجماعتين هو أنواع أنساع الاستبعادو التضمين ودرجاتهها. يكمن الفارق الثاني والأهم في المنهج المتّبع أو في

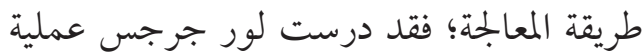
تحويل الأقباط إلى أقلية على المستويات كافتة لافت

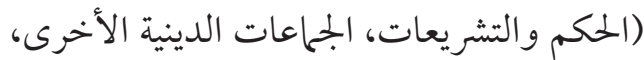

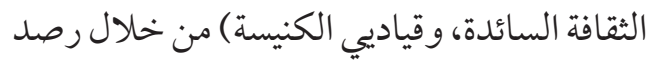
وتحليل الحوادث السياسية والاجتماعية الكاشفة الكائة

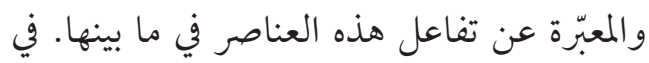

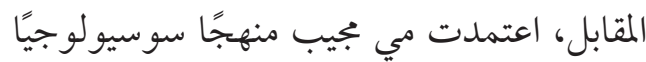
كلاسيكيًا مقارنًا (المعطيات الإحصائية المئية الكميّة،

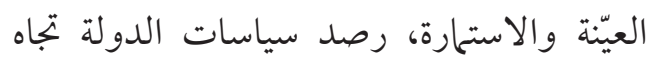

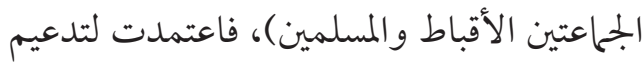
فرضياتها على المعلومات الإحصائية المتو افرة حول
الدول المعاصرة؛ فتتساءل المؤلّفة: هل يعني ذلك المُ استحالة قطع حلقة العنف الجماعاتي على المدىى

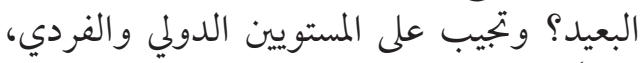

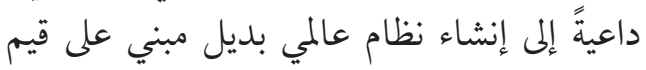
غير نفعية، واعتناق قيم جديدة (لا تحدّدها) كفيلة بتحويل العنف الداخلي الفردي (الكامن داخل جميع الأفراد) من الحيز الجلماعاتي إلى الحيز الإنساني

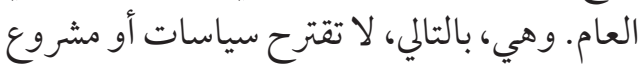

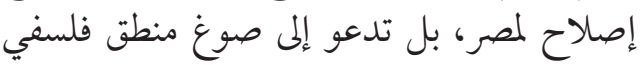
ثقافي وإنساني عالمي جديد.

\section{السياق البحتئي، والجديد في طرحها}

استندت لور جرجس إلى معظم ما نُشر بالعربية

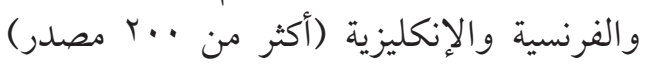

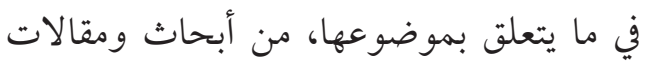

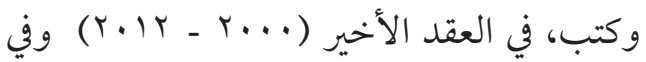
العقود الثلاثة السابقة. و واعتمدت على الحئ الوثائق

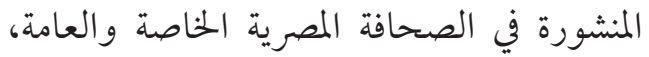

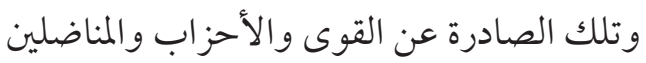
والسياسيين لرصد تفصيلات الحوادث الحزات الكاشفة الماتين

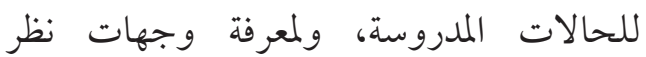

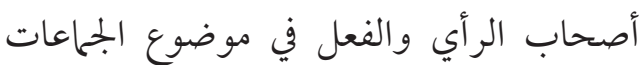

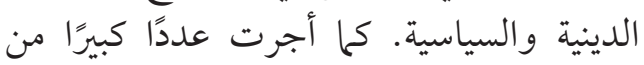

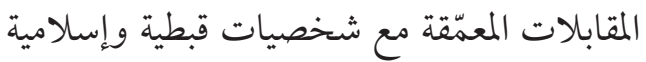

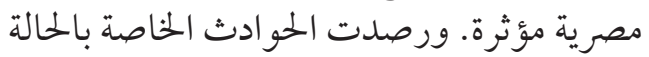

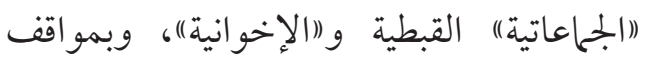
أصحاب السلطة وسلوكهم وسياساتهم، فيشكل

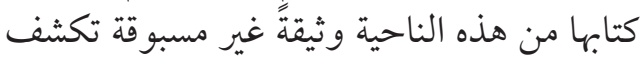
من زاوية المسألة القبطية تعقيدات الحية الحياة السياسية

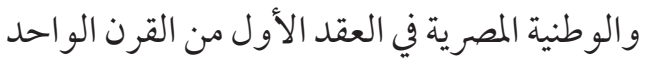

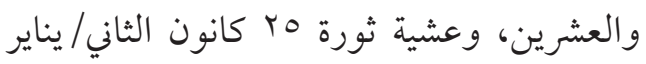

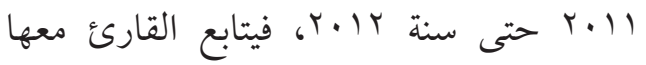
المخاض الصعب لتكوّن المواطنة المصرية على فئل أساس قانون مدني يساوي من دون تمييز بين جميع 
وعلى الرغم من اختلاف الحجم، فإن في الإمكان

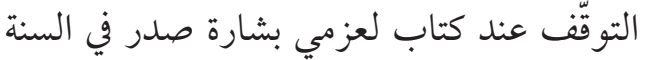

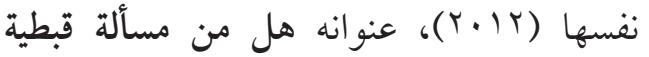

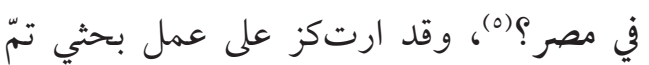

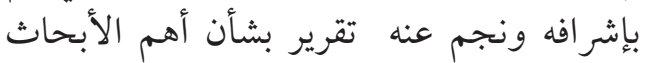

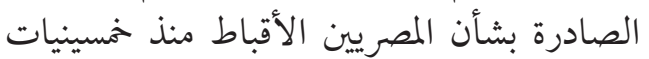

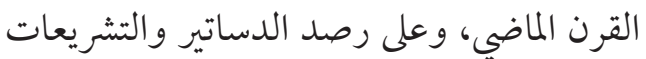

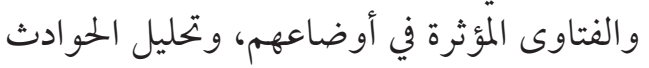
الطائفية البارزة التي وقعت في عهد فئ مبارك. تبرز نقاط التشابه مع دراسة لور جرجس من من المبن

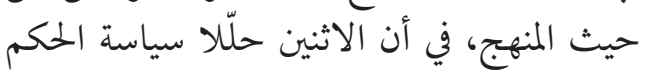

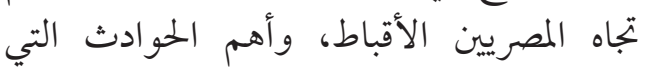
تظهر فيها حالات الإقصاء و التعنيف الجماعي. الخاطي.

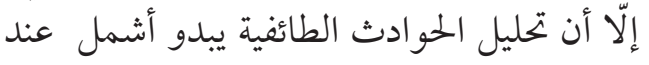
جرجس ( لاختلاف حجم الدراستين)، كونها

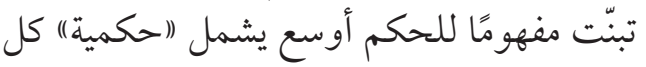

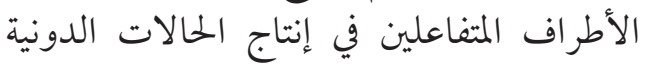

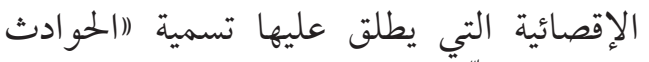

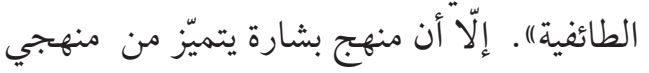

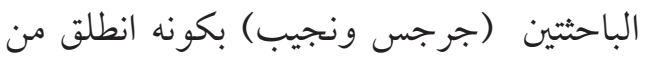

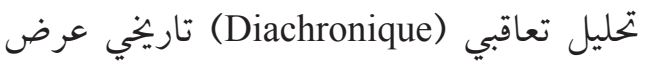
فيه بوضوح واقتضاب مسار قرنين من سياسات

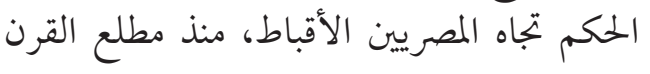

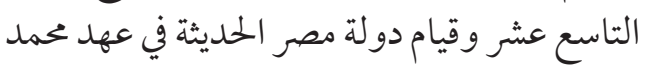
علي ثم في حكم الخديوي إسماعيل (وسياسات

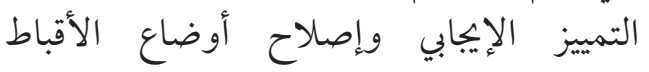

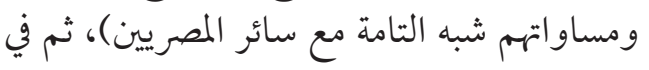

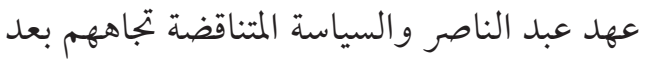

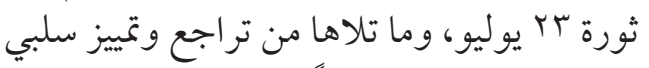

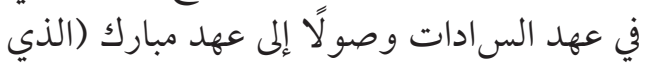
ترك للكنيسة إدارة شؤون ("جماعتها)").

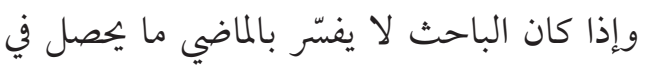

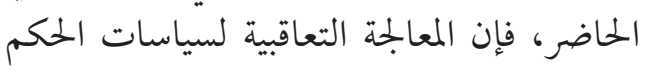

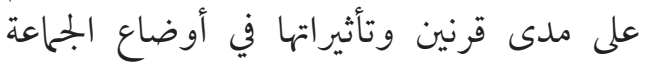

أوضاع الجماعتين وعلى آراء rيا فردًا من الأقباط

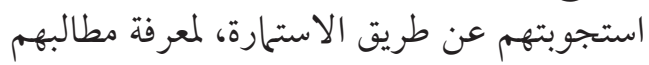

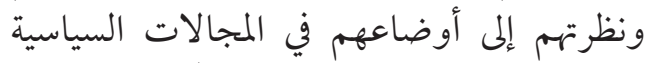

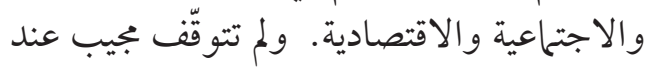

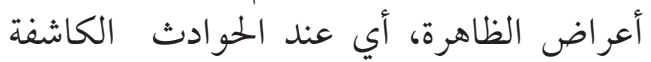

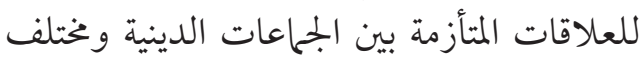
السلطات في المجتمع المصري.

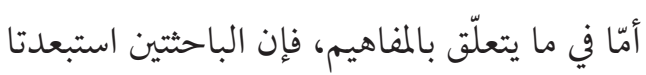

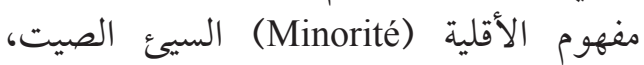
فاستبلته مي مجيب بمصطلح لمافلة محايد هو القلّة

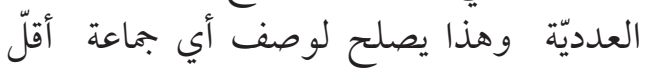

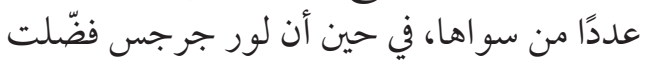

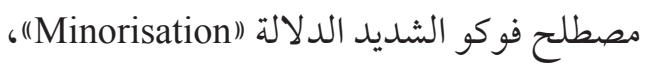

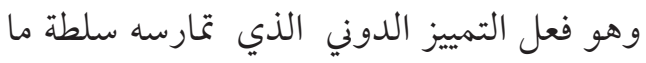

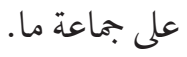

إذن، لدينا من ناحية منهجيةٌ تنقيبيةٌ متعددة

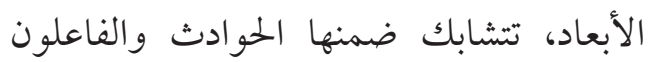
والمستويات، ولدينا من ناحية أخرى منهجيّة خطيّة الخئة

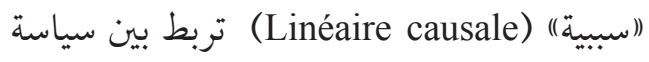

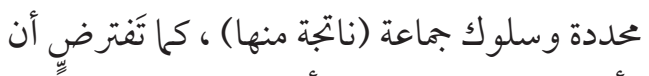

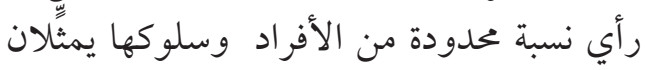

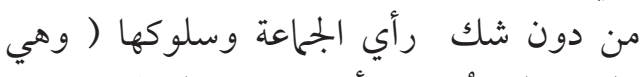

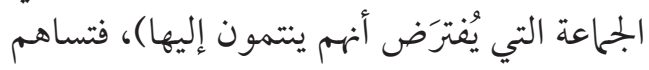

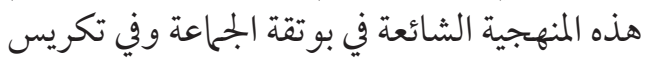

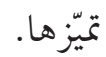
ولئن لم تقترح الباحثتان سياسات محددة لحل

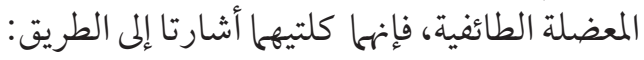
أشارت مجيب إلى بناء الدولة المصرية الحلديثة:

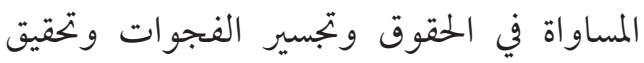

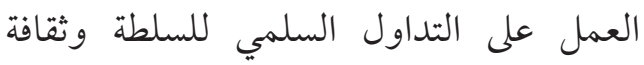
المو اطنة، وهي مطالب مرفوعة منذ أكثر من ثناثة العثة

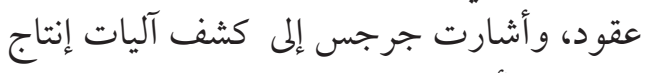

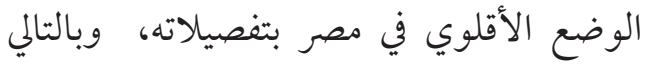
جعل عملية تفكيكه مككنة. 
وازدهار هذه الدولة، وبشكل لاحق أمن السكان

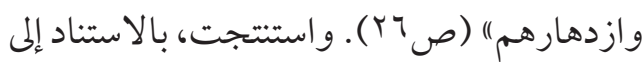

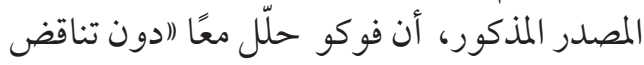

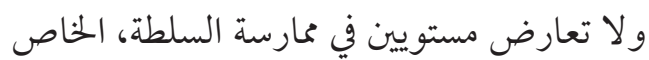

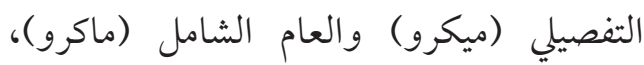
وإنه يمكن تأريخ نشأة الدولة من خلام الثال العال دراسة مارسات البشر في أفعالهم وطريقة تفكيرهم...

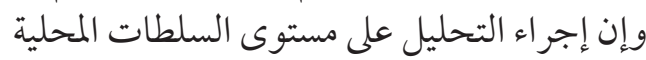

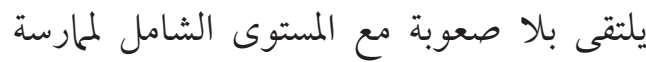
السلطة من قبل الحكومة والدولة)ا.

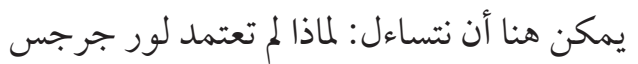

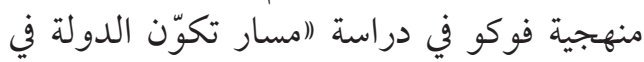

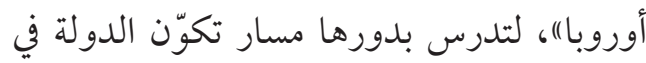

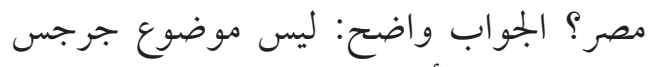
دراسة تكوّن (أو تعسّر) بناء الدولة في في مصرك،

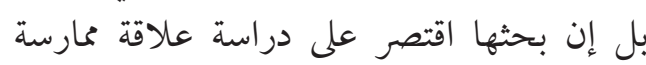

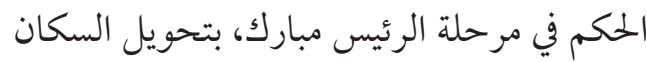

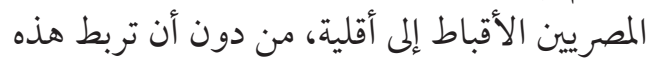
المارسة بطبيعة الدولة المصرية في الفترة ذاتها، المباك

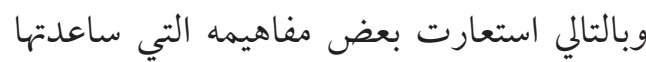
على الربط بين مستويات ثلاثة في ممارسة السلطة

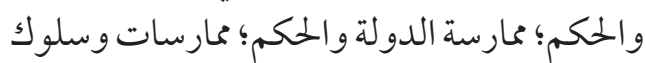

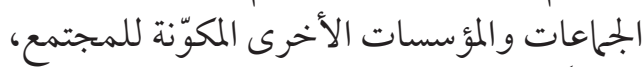

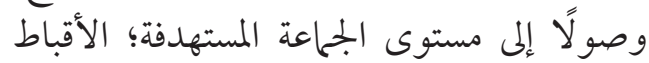

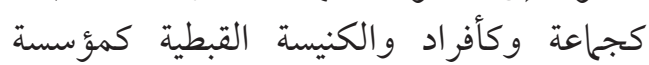

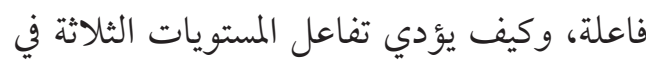

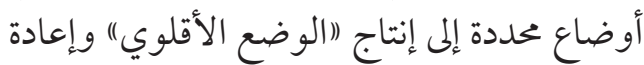

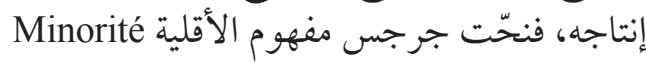

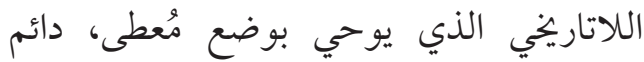

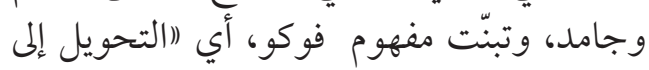

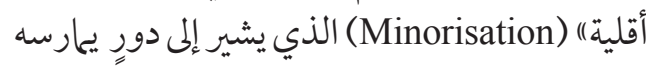
فاعلون سياسيون و مجتمعيون على جماعة من الناس

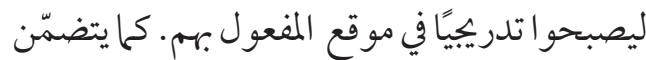

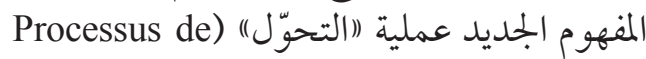
(minorisation
المصرية القبطية، تساعد على فهم ما تكوّن في ذاكرة

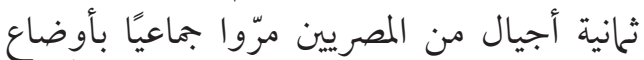

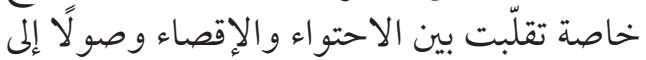

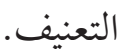
وعلى الرغم من أن المؤلفين الثلاثة استبعدوا تطبيق

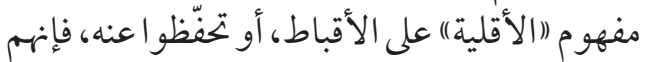

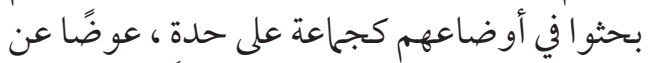

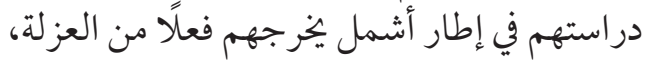

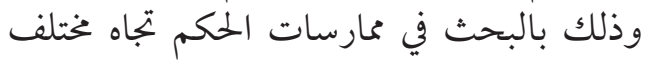
الجماعات القائمة في المجتمع المصري، الماتئ الدينية

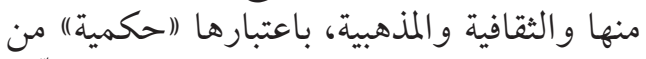

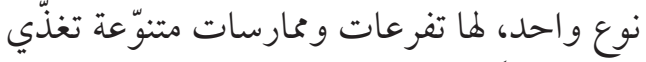
بعضها بعضًا وتعيد إنتاج نظام السلطات الساتئد في المجتمع. وبفضل الأبحاث الثاثة توصّلنا إلى الفرضية

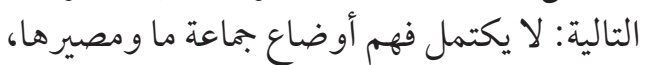

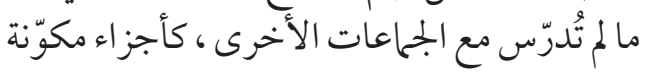

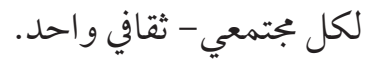

\section{المنهج والمفاهيه، ميشيل فوكو في الخلفية}

تشرح لور جرجس في مقدمة الكتاب المفاهيم

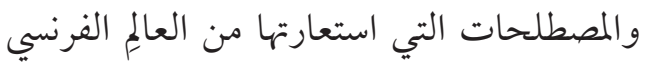

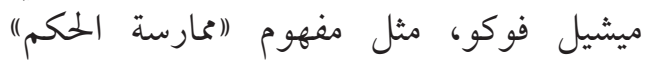
(Fouvernementalité) أقلية) (Minorisation) اللذين وردا في سيعاق

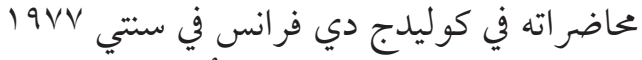

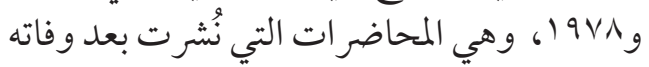

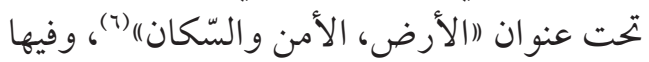

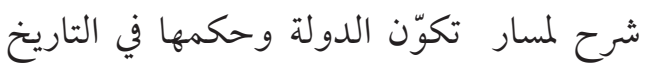

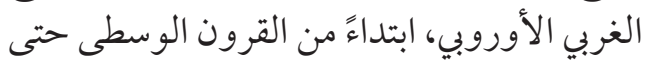

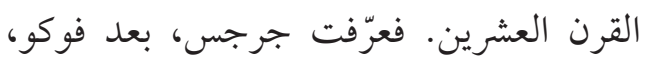

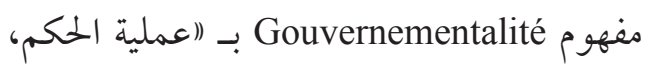
أي مجموعة الممارسات والآليات والخمات الخطابات والمؤسسات التي تُطبّنَ في دولة ما لضمانة أمن 
مو اطنين متساوين مع الآخرين. إلّا أن المؤلفة لم تعالج في كتابها هذه الناحية، أي السياسات

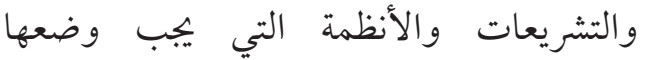
وتطبيقها على المستويات الثلاثة - الحكم و المجتمع والثي

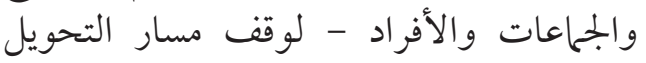

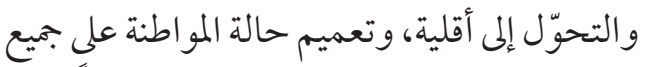

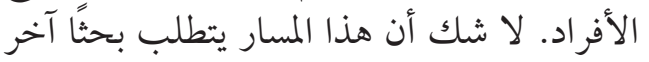
وأن الجهد الكبير الذي بذلته المؤلفة لفهم المسار

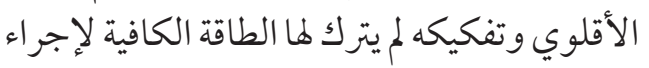

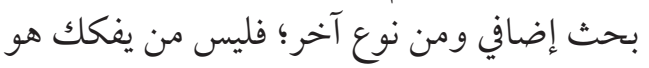

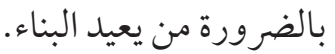

\section{هل يصلح منهج فوكو} ومفاهيمه

\section{لدراسة حالة الأقباط في مصر؟}

حدّد فوكو في درسٍ لـ مسار تكوّن الحكمي في مئي

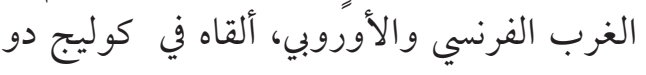

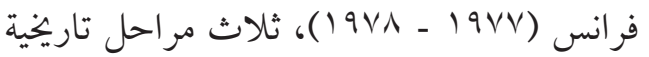

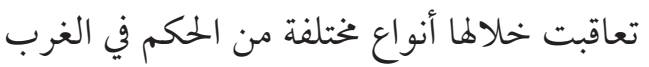

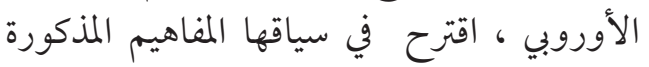

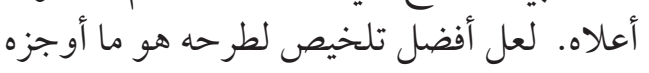

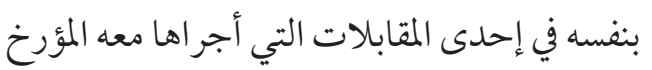

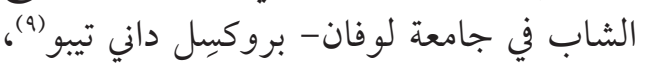
حيث شرح فوكو كيف اختار موضوعات أبرون أبحاثه وكيف درس موضوع فوكو السلطة في المجتمع الغربي

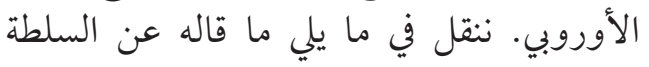

$$
\text { والحمىم (الترجمة من الفرنسية): }
$$

"السلطة هي مجموعة العلاقات التي تمكّن الواحد

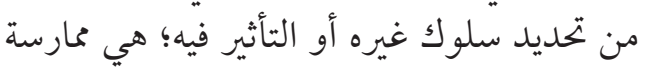

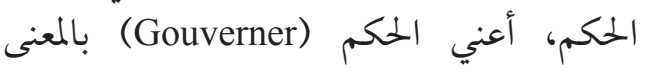

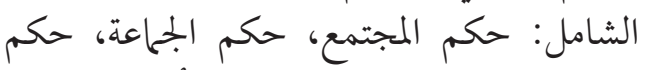

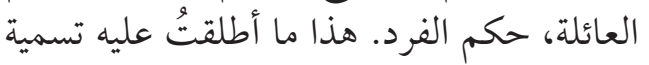

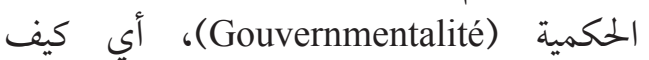
تُمارَس علاقات السلطة، وكيف يُمارَس الحكمم
يشرح فوكو في محاضراته المعنونة يجب الدفاع عن المن المناع

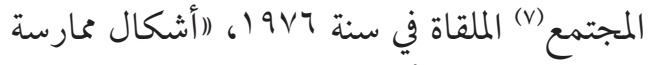
الدولة عنفها)، وأشكال استبعادها، واضطهادهادها

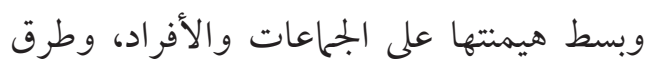

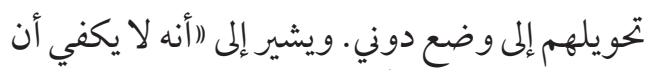

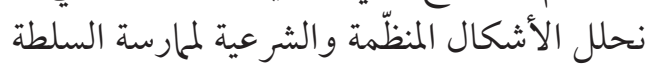

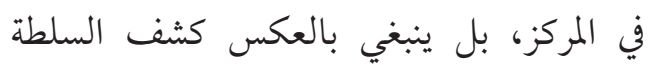

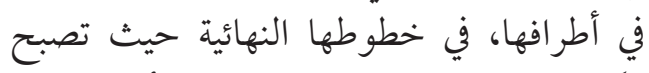

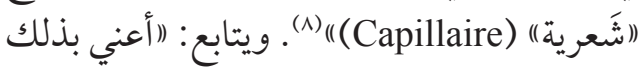

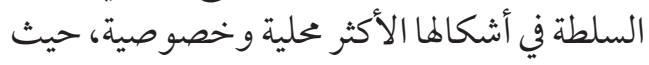

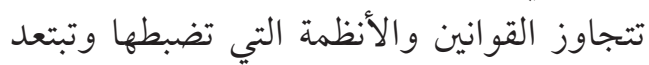

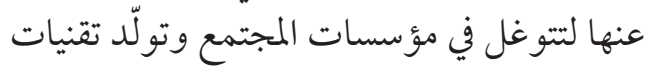

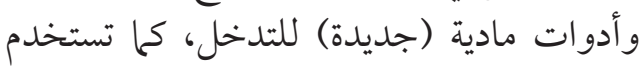

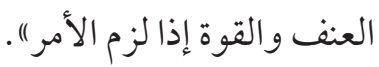

بالاستناد إلى هذين المفهومين، عملت الماتل

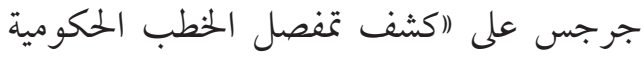

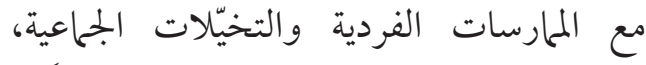

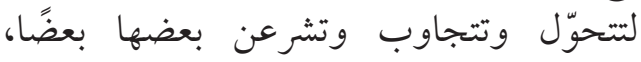
وتساهم في إنتاج وإعادة إنتاج نظام ذات دئ دلالة مبني على منطق إقصاء (Ordre signifiant)

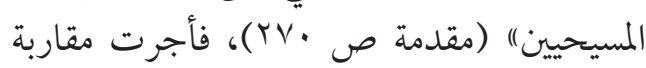

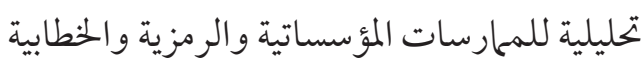
الصادرة عن مختلف أنواع السلطات المؤثّرة في المئية

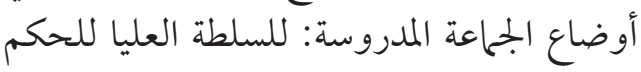

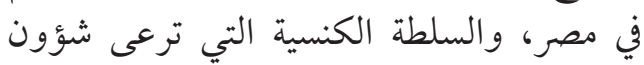
الأقباط المنتمين إليها، والجحاعات الريلة الرعوية القائمة

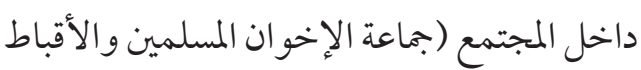

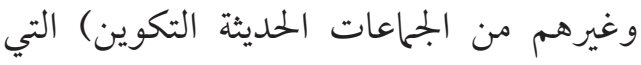

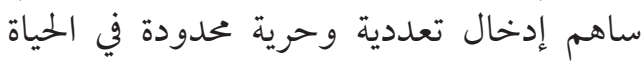
السياسية في تأجيج الصراع بينهم.

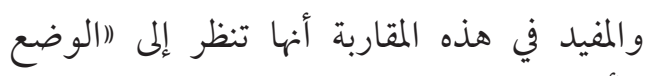

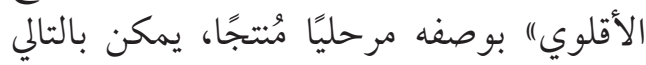

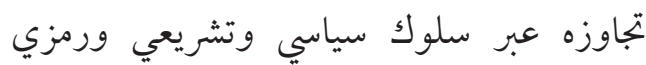
مختلف، وتحويل الذين وُضعبوا فيه إلى وضع ورئ 
لم تتوقف المؤلفة بها فيه الكفاية عند توصيف نوع الحكم في الدولة المصرية الحديثة التي نشأت وتكوّنت بعد الثورة الناصرية وكانت في بدايتها (في رأيي) تنموية ورعائية (عادلة)) (مع دور كبير

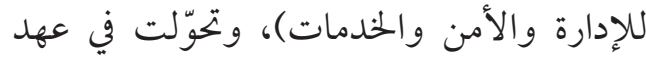
السادات إلى دولة هجينة احتفظت بإدارة متضخّمة فئمة

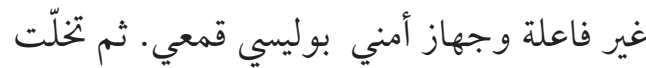

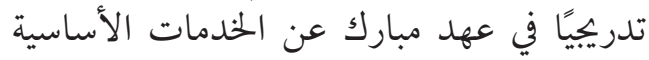
التي تقدّمها عادة الدولة الرعائية (الاشتراكية)

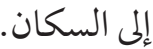

إن تخلي الدولة المصرية في عهدي السادات ومبارك، وبصورة متزايدة، عن دورها الرئة الرعائي

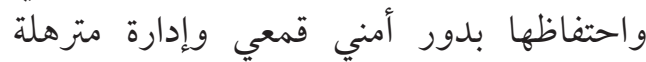

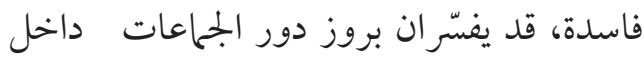

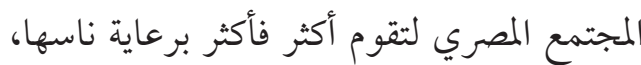
فتصاعد دور جماعة الإخوان المضطهَّدة والمقصصاة

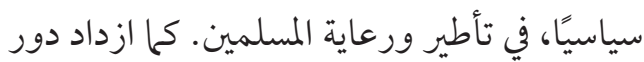
الكنيسة في تأطير الأقباط ورعائة المليتهم وحمايتهم اردادور

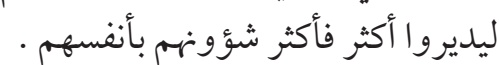
وبالتالي، يبدو أن المؤلفة طبّت مفهوم (الحكمية)"

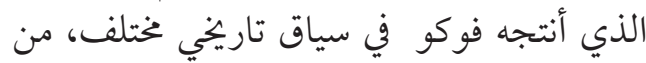

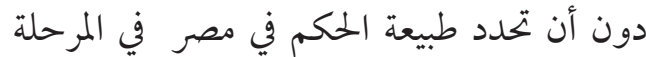
الناصرية وفي عهد مبارك. إلّا أن وصفها الدقيق المريق

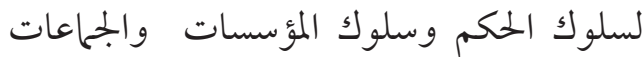

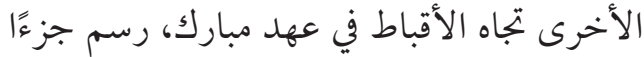

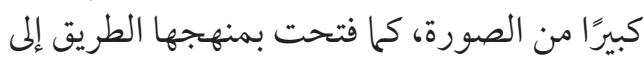

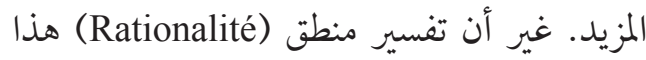

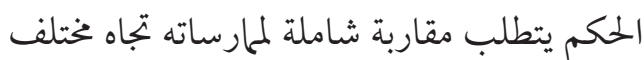

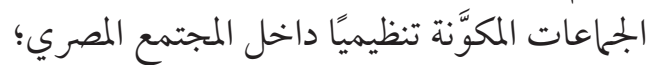

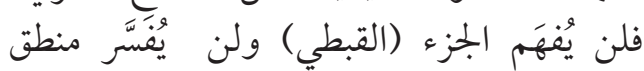

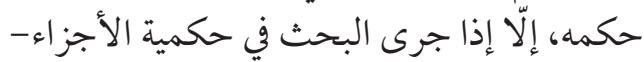

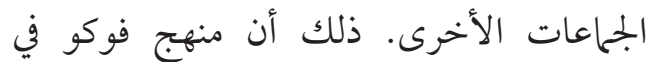

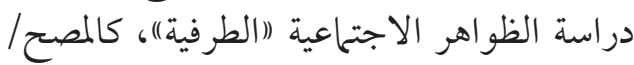

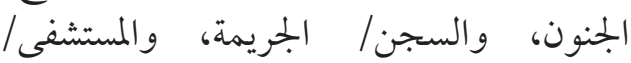

(على المستويات كافة). خلال المرحلة الأولى في

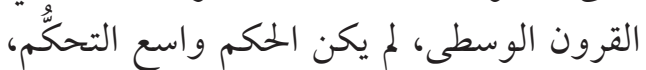

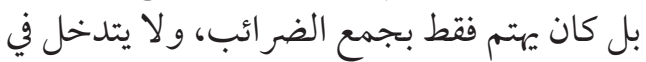
شؤون الناس. في المرحلة الثانية الرعائية الكنسية (في القرنين السادس (Pastorale ecclesiale)

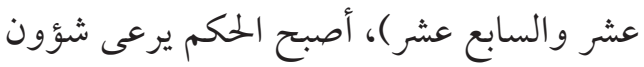

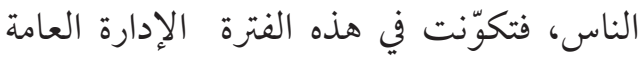

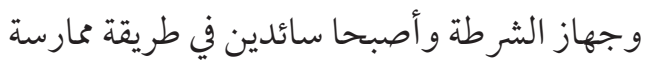
الحكم، يقومان بأدوار تنظيمية وتأديبية قمعية.

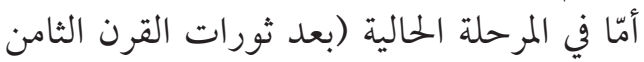

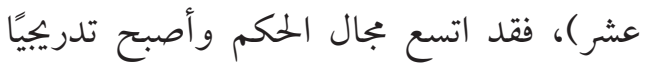

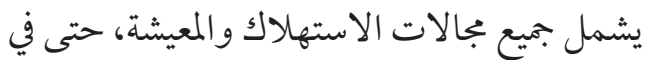

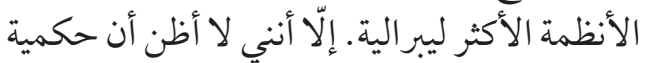

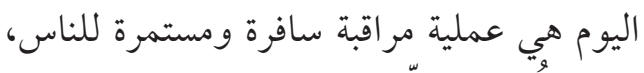

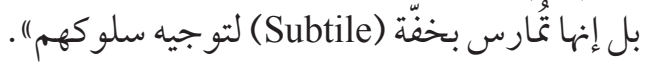

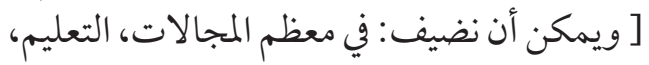
و الصحة و السكن و الغذاء والاستهلاك، و الإعلام و التنّّل.... إلخ].

إن الصعوبة الأولى في منهج فوكو هي في تحديد الحكان

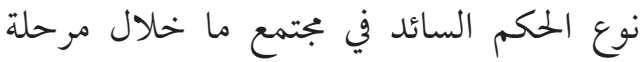

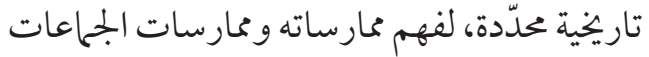
والأفراد المشمولين في حكمه وتفنسيرها. هل

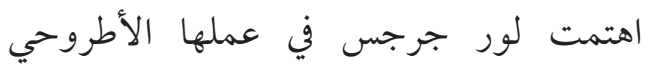

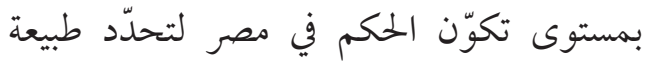
السلطة والحكم في الحقبة الزمنية المختارة، ولكي الميكي تربط مسار التحويل إلى أقليّة بنوع الحمكم السائد المئد

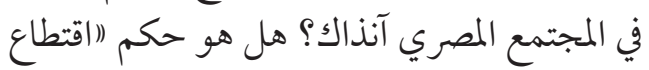

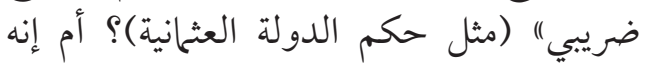
رعائي يسود فيه الجهاز الإداري والبوليسي (شبيه

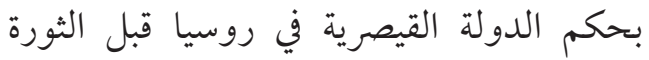
البولشفية)، ويترك للناس وللجاعراعات والعائلات

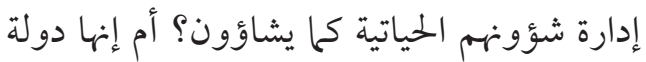

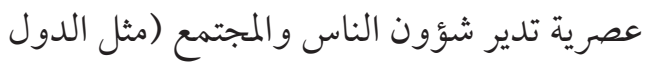

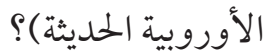




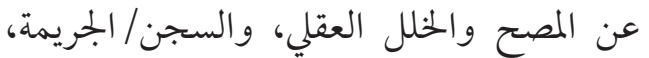

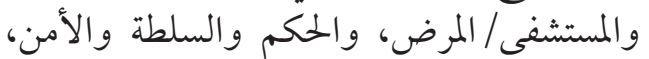

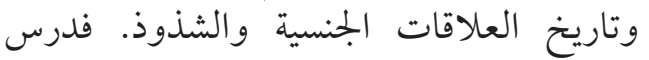

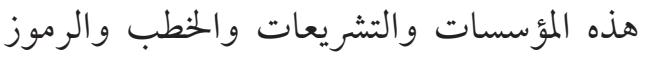

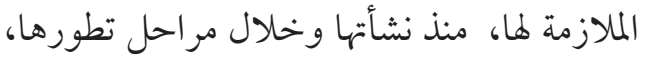

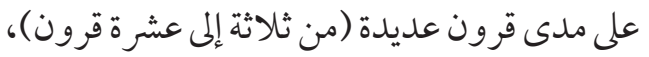

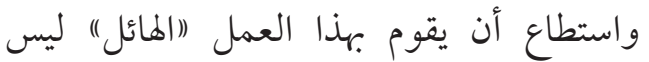

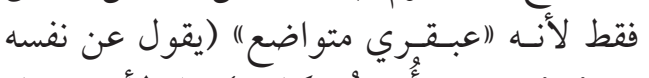

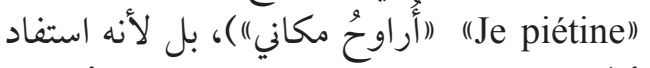

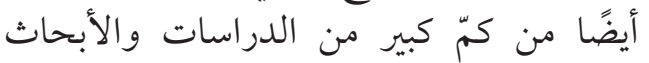

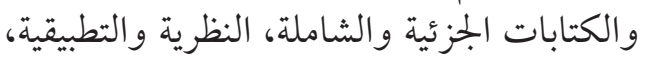

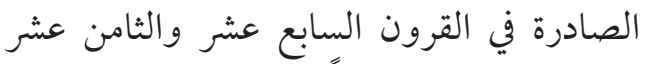

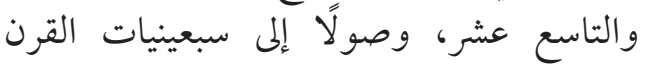

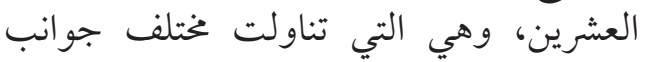
الظاهرة المدروسة، فاستطاع بذهي تلذهنه التوليفي

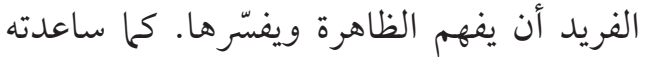

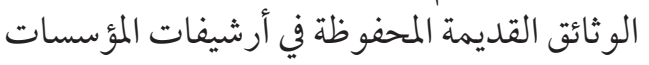

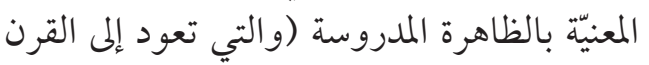

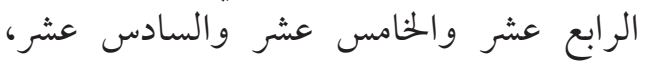

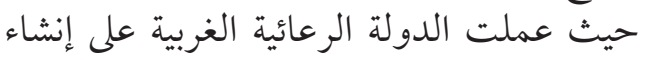

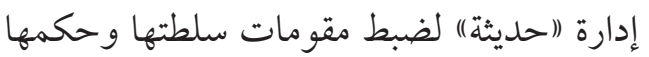

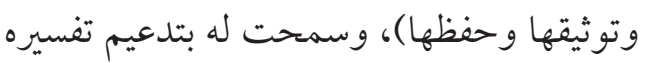
التوليفي (Synthèse) بالحجج والأمثلة، من أجلان

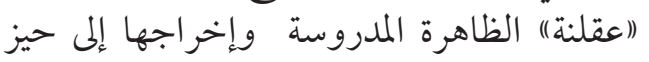

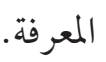

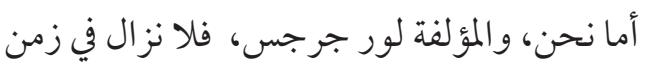

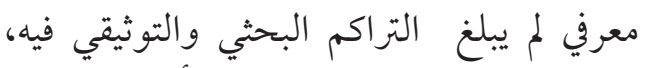

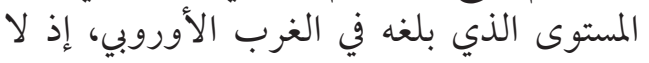

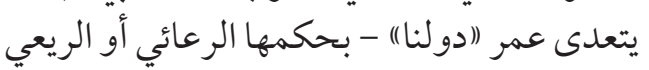

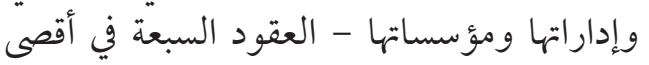

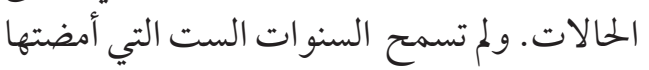

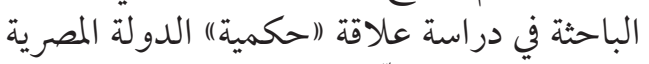

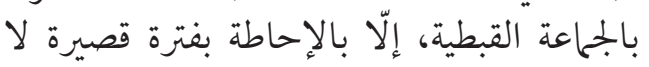

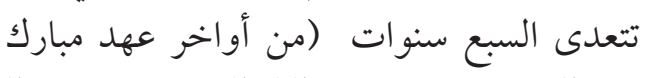
ro ro r..0 يناير ) ، كما والاقتصار على التنقيب في التفاعلات
المرض، والسلوك الجنسي/ الانحراف، لا يركّز

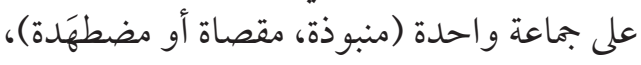

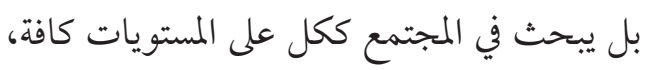

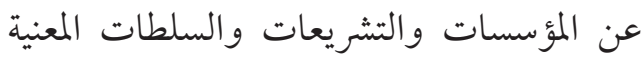

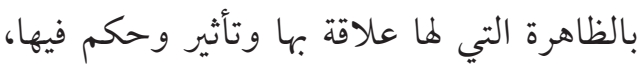
فيكشف في نهاية المطاف (والبحثث) الأفراد البهاد

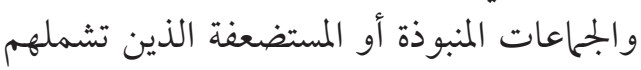

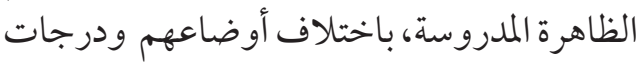

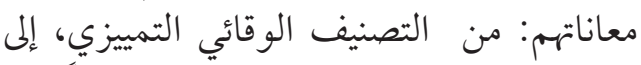

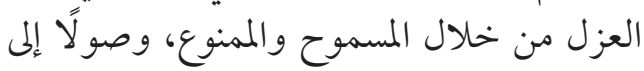

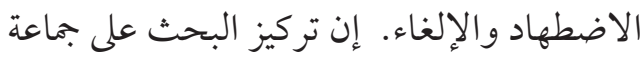
واحدة دون الجحاعات الأخرى التي تعاني أنواعًا

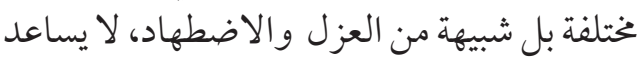

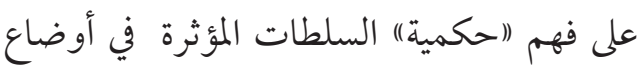
هذه الجماعات، وتفسير (عقلنة) ممارسات هذاته الجماعات المتأثثرثة بحكمهيا. وتفير.

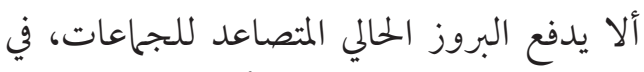

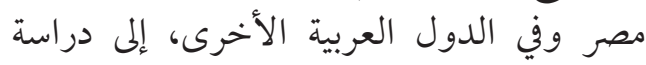

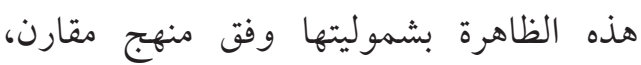
يضع توصيف نوع (الحكمية) السائد/ المتغيّر في الصدارة والسلطات المنبثقة عنه والمناهضة له؟ قد قد

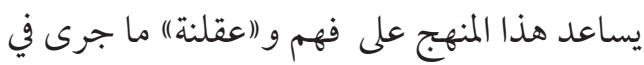

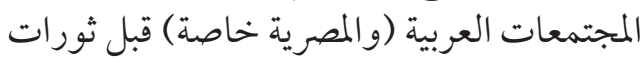

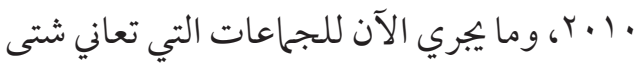
أنواع العزل و والاضطهاد، كما التي تمارس تجان التاه

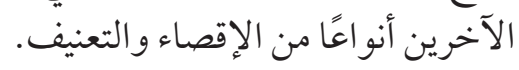

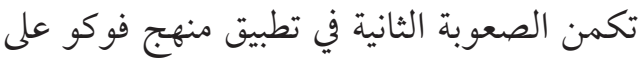

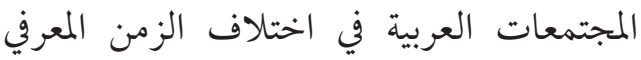

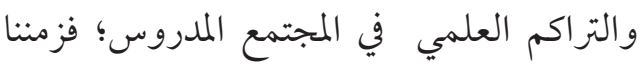

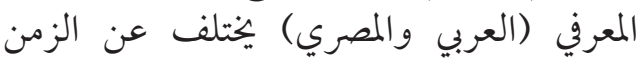
ألمعرفي الذي أجرى فيه فوكو أبحاثه (فرنسا

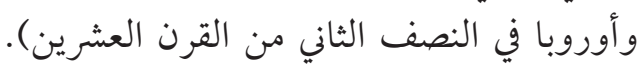
إذ استطاع فوكو أن ينتج خلال الأربعين عامًا لأنا

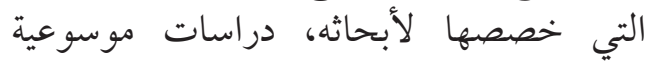


$<\mathrm{http}$ ///religion.info/french/articles/article_501.shtml\#. UqBU2s_8L5p>.

(3) Sarah Ben Nefissa et Blandine Destremau, dirs, Protestations sociales, révolutions civiles: Transformation du politique dans la Méditerranée arabe, revue Tiers Monde. Hors série (Paris: Armand Colin, 2011).

(ع) مي مجيب عبد المنعم مسعد، الأقباط ومطالبهم في مصر

بين التضمين والاستبعاد، سلسلة أطروحات الدكتوراه؛ ع •

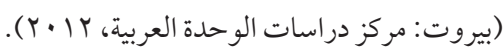

(0) عزمي بشارة، هل من مسألة قبطية في مصر؟ (بيروت؛ مركن

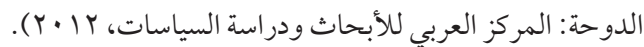

(6) Michel Foucault, Sécurité, territoire, population: Cours au Collège de France, 1977-1978, éd. établie par Michel Senellart; sous la dir. de François Ewald et Alessandro Fontana, hautes études (Paris: Gallimard; Seuil, 2004). 1986

(V) Minorisation Michel Foucault, "Il faut défendre la société": Cours au Collège de France, 1975-1976, éd. établie, dans le cadre de l'Association pour le Centre Michel Foucault par Mauro Bertiani et Alessandro Fontana; sous la dir. de François Ewald et Alessandro Fontana, hautes études (Paris: Gallimard, 1997).1986.

(^) التشبيه مقتبس من الأوعية الشعرية الدموية في الجسد. (4) (1986)

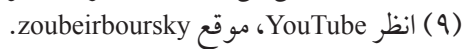

الخاصة بججاعة و احدة .

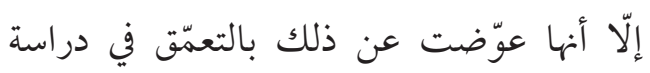
مجمل العلاقات بين هذه الجماعة و وكنيستها،

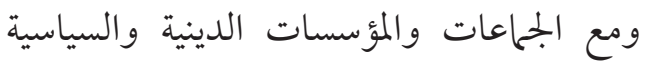
الأخرى، كما والعلاقات المتبادلة بين الكنيسة

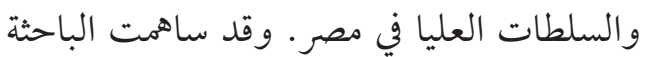

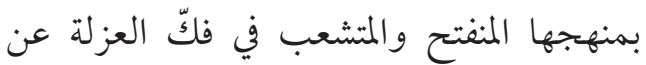

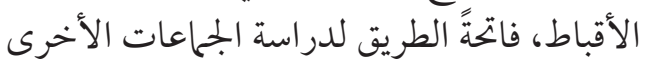

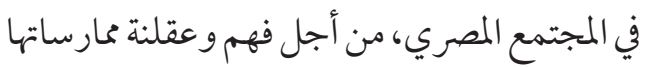

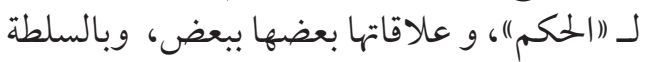

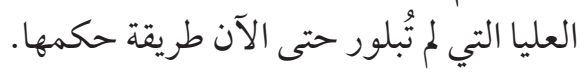

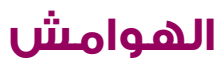

(1) Conversions religieuses et mutations politiques en Egypte: Tares et avatars du communautarisme égyptien, coordination, présentation et traductions par Laure Guirguis; préface de Bernard Heyberger (Paris: Non Lieu, 2008).

(2) Laure Guirguis, "Egypte: L'Autre succession, l'église copte à l'approche d'un tournant," (Institut Religioscopie, 7 October 2010), disponible sur le site éléctronique: 